\title{
Prostorski stroji gledališča kot dinamika prestopanja meja semiotičnih sistemov
}

Ključne besede: Robert Wilson, Emmanuel Demarcy-Mota, Vito Taufer, prostorski obrat, prostorska dramaturgija, dramaturgija zvoka, semiosfera

DOI: $10.4312 /$ ars.13.2.268-284

\section{Kako definirati semiotični prostor gledališča?}

Članek bo sledil Lotmanovim osnovnim postavkam, s pomočjo katerih določa semiotični prostor, $\mathrm{z}$ namenom na primerih sodobnih uprizoritvenih korpusov, gledaliških, plesnih in hibridnih predstav pokazati, na kakšen način uprizarjanje ustvarja semiotične jezike, ki niso enostavna vsota posameznih znakovnih sistemov, ampak v dinamični interaktivnosti vzpostavljajo gledališki dogodek. Gledališko predstavo bomo analizirali kot semiotični prostor prehodnih oblik, ki nastajajo med različnimi mediji. Hkrati nas bodo zanimala prestopanja meja med odrom in avditorijem, igralci in gledalci, ki se skozi proces kreacije in recepcije ter v dinamiki avtopoetične povratne zanke spreminjajo.

Naša začetna teza je, da so jeziki, ki zapolnjujejo "semiotično prostranstvo« predstave, ${ }^{1}$ raznoliki in da je prav ta raznolikost kvaliteta, ki omogoča prehajanje oziroma prebijanje meja znotraj polja kreacije in recepcije. Pri tem nas bosta zanimala lotmanovsko definirani »vmesni položaj gledališča med gibljivim in nediskretnim svetom realnosti ter negibljivim in diskretnim svetom upodabljajočih umetnosti, ki provocirata dinamiko izmenjave kodov med gledališčem in upodabljajočimi umetnostmi« (Lotman, 2006, 93), ter navezava na Rancièrjev pojem emancipiranega gledalca, ki odnos med igralci, ki kot raziskovalci gradijo oder, in gledalci, ki igrajo vlogo aktivnih interpretov, ustvarjajočih lasten prevod, razume predvsem kot emancipirano skupnost pripovedovalcev in prevajalcev. Zanimalo nas bo, kateri od reformističnih smeri gledališča 20. stoletja so zapisane sodobne produkcije; tako bomo sledili Rancièrjevi misli, da so moderni poskusi reformiranja gledališča od Brechta in Artauda dalje vztrajno nihali med dvema poloma, dvema formulama.

1 S pojmom semiotično prostranstvo predstave Lotmanovo terminologijo uporabimo za opis specifičnosti semiotičnega prostora in semiosfere, kot ga je razvijal predvsem $\mathrm{v}$ analizah literature in filma, na področju uprizoritvenih praks. 
Po prvi je gledalca treba iztrgati iz omamljenosti zijala, očaranega od videza in polnega empatije, zaradi katere se identificira $z$ odrskimi osebami. Postavljen bo torej pred čudno, neobičajno predstavo, uganko, katere smisel bo moral iskati. Tako bo prisiljen, da položaj pasivnega gledalca zamenja za položaj preiskovalca ali znanstvenega eksperimentatorja, ki raziskuje pojave in njihove vzroke. [...] Po drugi formuli je treba ukiniti prav to modrujočo distanco. Gledalca je treba potegniti iz položaja opazovalca, ki si mirno ogleduje ponujeno predstavo. Treba mu je odvzeti to iluzorno obvladovanje, ga potegniti v čarobni krog gledališke akcije, kjer bo privilegij racionalnega opazovalca zamenjal za privilegij bitja, ki razpolaga s celoto svojih vitalnih energij (Rancière, 2010, 9).

Hkrati nas bo zanimalo, na kakšne načine prostor igre in gledanja postane stvar prevajanja v Bourriaudovem smislu: „Altermoderna umetnost se torej bere kot nekakšen hipertekst; umetniki prevajajo in prekodirajo informacije iz enega koda v drugega« (Bourriaud, 2009a). Gre torej za umetnost, razumljeno kot raziskovanje vezi, ki se pletejo med besedo in sliko, časom in prostorom. Gledališki prostor postane prehajanje iz ene kulturne krajine $\mathrm{v}$ drugo, ki ustvarja nove poti med množico izraznih in komunikacijskih oblik. Ali, povedano z Lotmanom: nastane dinamika semiotičnih jezikov v prostoru, ki niso enostavna vsota posameznih znakovnih sistemov, ampak $\mathrm{v}$ interaktivnosti vzpostavljajo gledališki dogodek. Ta je v veliki meri odvisen od tega, kar Lotman poimenuje odnos med tekstom in publiko, za katerega je značilna »medsebojna aktivnost: tekst teži k temu, da bi prilagodil publiko sebi, ji vsilil svoj sistem kodov, publika pa mu odgovarja na enak način« (Lotman, 2006, 97).

Dinamika semiotičnih jezikov, ki nastane na odru, je potemtakem značilna tako za drugo paradigmo gledališke predstave kot za tretjo paradigmo recepcije, odnos med tekstom oziroma predstavo, ki vplivata na sprejemnike. Hkrati pa ti receptorji (kot bi dejal Roland Barthes) tudi sami kreirajo predstavo skozi svoje prevajanje teksta, prostora in drugih elementov predstave. Prav o tem govori Lotman, ko poudarja, kako mora za to, da se "preprost prenos sporočila spremeni v ustvarjalni proces [...], postati semiotična struktura sprejemnika bolj zapletena: sprejemnik je osebnost « (prav tam, 105). Dinamika semiotičnih jezikov recepcije predstave je še večja, kadar so »ustvarjalne možnosti sprejemnika skrajno aktivizirane» (prav tam).

Lotmanovo branje prostora je (podobno kot veliko drugih, na primer tisto Erike Fischer-Lichte in Benjamina Wihstutza v Performance and the Politics of Space (2012) ali Gaya McAuleyja in njegove knjige Space in Performance: Making Meaning in the Theatre, 2000) semiotično; prostor bere kot enega izmed številnih jezikov ali znakovnih sistemov, ki so na delu v predstavi. Današnji teoretiki prostora in prostorskega obrata 
tako govorijo o konceptualnem, mimetičnem in označevalnem prostoru ter strategijah prostorskega prilaščanja. Velikokrat izhajajo iz Lefebvrovega koncepta prostora kot družbeno proizvedene in ne že kar same po sebi dane entitete (Lefebvre, 1974). Vsi pa so si edini, da je gledališče »umetnost časa in prostora« (Aronson, 2013, 84).

Kakorkoli že se pozicioniramo, bodisi znotraj semiotične bodisi fenomenološke bodisi materialistične analize, priznavamo, da je naš vsakdan povezan s popotovanji po različnih scenografijah, od dejanskih do virtualnih, zasebnih do javnih, uprizorjenih do neuprizorjenih, znanih do neznanih. Ves čas gre za dvosmerno dinamiko, prostor definira človeške akcije, te pa vzvratno spreminjajo prostor. V nadaljevanju si bomo s pomočjo preverjanja uporabnosti Lotmanovih semiotičnih raziskav in naslonitve nanje podrobneje ogledali šest primerov te dvosmerne dinamike, kot se udejanja bodisi na odru bodisi v avditoriju ali v avtopoetični povratni zanki med obema, izvajalci in občinstvom, na odru in v parterju.

\section{Prostorska dramaturgiija}

Naš prvi primer, s pomočjo katerega bomo raziskovali, na kakšen način uprizarjanje ustvarja semiotične jezike, ki niso enostavna vsota posameznih znakovnih sistemov, ampak v dinamični interaktivnosti vzpostavljajo gledališki dogodek, bo hommage pionirju sodobnega baleta in hkrati eni ključnih figur modernistične umetnosti 20. stoletja Vaclavu Nižinskemu, ki sta ga pod naslovom Letter to a $\mathrm{Man}^{2}$ skupaj ustvarila pionir gledališča podob Robert Wilson in eden ključnih reformatorjev sodobnega baleta Mihail Barišnikov. Wilson svojo predstavo gradi kot kontrapunkt in hkrati kot bachovsko fugo različnih znakovnih sistemov. Pri tem ga ne zanima Nižinski kot fenomen semiotičnega in semantičnega telesa na baletnem odru, ampak Nižinski kot padla ikona modernistične umetnosti 20. stoletja. Vizualno črpa iz heterogenih virov, od ekspresionističnega Munchovega Krika do vaudevillske estetike zgodnjega Hollywooda.

Barišnikov je tako na odru vzporedno mnoštvo pomenjanj: je hkrati v vseh protislovjih recepcije, ki se sprožajo, favn, klovn, vampir, vaudevillski igralec, bolnik, nadrealistični lik iz Gogolja ali paranoični lik iz Dostojevskega. Tudi zvokovno je predstava izrazito kontrastna, tišina in gibanje sta za Wilsona le dve strani iste resničnosti, ki se ves čas izmenjujeta, izrinjata druga drugo. Glasba Hala Willnerja je eklektični hibrid, v katerem se izmenjujejo in prekinjajo Bob Dylan, Arvo Pärt in kabaretna glasba. Tako predstava ustvarja posebno obliko zvočnega prostora

2 Robert Wilson / Mikhail Barišnikov: Letter to a Man, režija, scenografija in lučni koncept Robert Wilson, izvaja Mikhail Barišnikov, koprodukcija Spoleto Festival dei 2Mondi, BAM, Cal Performances University of California Berkeley, Center for the Art of Performance at UCLA, 2015; ogledali smo si predstavo 20. januarja 2017 v Espace Pierre Cardin, Théâtre de la Ville, Pariz. 
oziroma prostora zvoka. Besedilo sampla in kombinira skozi ponavljanje fragmentov iz dnevnikov Nižinskega, ki delujejo kubično natančno, vzpostavljajo dinamično postdramsko, a dramatično strukturo Darryla Pinckneyja, hkrati pa zavestno ne producirajo razumljive avtorske interpretacije. Nižinski je prisoten v različnih glasovih, ki so velikokrat modulirani, ob Barišnikovem, ki se svobodno giblje po labirintih angleščine in ruščine $\mathrm{z}$ različnimi stopnjami naglasov, tudi $\mathrm{v}$ glasovih Wilsona in koreografke Lucinde Childs.

Kljub izjemnosti in neponovljivosti palete gibov, ki jih generira Barišnikov $\mathrm{v}$ natančni koreografiji, ki jo podpisuje skupaj z Wilsonom in Lucindo Childs, se skozi eklektično povezavo glasu, giba in slike, zasnovano na biografskih elementih Nižinskega, ustvarja nekoliko groteskna slika plesalca-slehernika v ogledalu njegovega uma, v katerem se resničnost kaže skozi optiko paranoje. S pomočjo vsega tega lahko na svojo grozo odkrijemo, da je norost tista, ki generira dramatičnost. Toda ta norost ni zgolj klinična, ampak je posebni esprit badioujevskega 20. stoletja vojn in uničenj starega, ki ne proizvedejo veliko novega.

Pri Wilsonu so za dramaturgijo od zgodbenih in besedilnih skoraj vedno pomembnejša prostorska načela. Lahko bi rekli, da po Lotmanu izpostavlja vmesni položaj gledališča med gibljivim in nediskretnim svetom realnosti ter negibljivim in diskretnim svetom upodabljajočih umetnosti. Prostor njegovih predstav je kronotopičen, hkrati pa izrazito dinamičen v smislu Lotmanove semiosfere. Wilson in Barišnikov tudi tokrat proizvedeta to, kar Heidi Taylor poimenuje »nepredvidljivost in fluidnost elementov«, ki predstave ne poskuša nadzorovati, ampak jo sprejme. Pri tem avtorja proizvedeta specifično dramaturgijo, ki ji ne umanjka dinamičnost, a se odreče enemu samemu pripovednemu loku (Taylor, 2004, 18). Povedano z Bourriaudom (2009b): prevajata in prekodirata informacije iz enega koda $\mathrm{v}$ drugega.

Barišnikova kot performerja zaznamuje tipično wilsonovski govorec-interpret, ki ga ves čas spremlja njegov - večkrat in na različne načine moduliran - lasten glas, ki pa je le redko ali nikoli prav njegov, oseben, zaseben, igralsko-interpretativen. Proizvaja stavke in izjave, ki tako kot njegove geste ne pripadajo zgolj njemu, ampak predvsem prostoru-času predstave. Jezik in govor, ki ju proizvaja, sta del prostorskega, ne pa zapisanega teksta.

Dramaturgija predstave je tako hkrati govorna in prostorska, zvočna in govorna. Barišnikov kot igralec-izvajalec-kreator gradi oder, gledalci pa so aktivni interpreti, ki kreirajo lasten prevod, prevajanje $\mathrm{v}$ Bourriaudovem smislu: umetnost kot raziskovanje vezi, ki se pletejo med besedo in sliko, časom in prostorom (prav tam). V tem smislu je treba razumeti tudi slovito Wilsonovo izjavo: »Prisluhnite slikam « ${ }^{3}$ - ne kot potrebo 
po preprosti sinesteziji ali postdramskem gledališkem triku, ampak v smislu Bonnie Marranca, njenega razumevanja gledališča podob in Lotmanovega razumevanja umetniških del kot sistemov delovanja jezikov, ki zapolnjujejo semiotično prostranstvo predstave, so raznoliki in omogočajo prehajanje oziroma prebijanje meja znotraj polja kreacije in recepcije. Robert Wilson prostor, svetlobo, zvok in gibanje tke oziroma prepleta v odprto, nenavadno tkanino, ki pozornemu poslušalcu in gledalcu omogoča, da razišče široko pomensko polje.

Odrski prostor razume kot proces v času, kot predstavitev podob, ki se izogiba tradicionalnemu pojmu zgodbe ali sižeja. Prepričan je, da je bolj kot »realizem« na odru produktiven formalizem: »Pri ustvarjanju mi je bližji, ker ustvarja več razdalje, več mentalnega prostora.« Prav strukturno, proceduralno, čustveno in vizualno nadzorovano gledališko stanje ustvarja » prostor « za resnično: »Pogosto čutim, da to, kar vidim na odru, temelji na laži, « pravi o tradicionalnem gledališču. »Veste, igralec misli, da je naraven, vendar ni, deluje naravno in to je nekaj, kar je umetno. Z umetnostjo, mislim, da lahko ... veš več o sebi, se lahko približaš ... resnici« (Schechner, Friedman, 2003, 120).

\section{Zvokovni prostor}

Kot drugi primer pletenja zvokovnega prostora bomo navedli projekte performerke, pevke in filozofinje Irene Tomažin Zagoričnik, ${ }^{4}$ ki uporablja predvsem lasten nemoderiran glas, a ga razpomenja in opomenja na inovativne načine. Tako odpira medbesedilne oziroma medmedijske reference, ki jih generirata bistvena elementa dramaturgije zvoka in prostora: telesno, gestično igralčevega glasu in strukturne lastnosti zvoka, ki ga in se ustvarja v prostoru. Izhajajoč iz raziskav Heinerja Goebbelsa in Christopha Marthallerja, pa tudi Meredith Monk, ustvarja prostorske zvokovne elemente, zvokovno-prostorsko partituro kot interakcijo vokalizacije in fenomenalnega telesa performerke $v$ gibanju in statičnosti.

je na nek način res bližje obnašanju živali. Ko pes zalezuje ptico, posluša celo telo. Ne posluša z ušesi in z glavo; je celo telo. Oči poslušajo." (Schechner, Friedman 2003, 120).

4 Irena Tomažin Zagoričnik (1979, Ljubljana) je študij filozofije zaključila na Filozofski fakulteti v Ljubljani. Večinoma deluje in ustvarja v gibalno-gledaliških predstavah ter na področju eksperimentalne improvizirane glasbe. Doslej je ustvarila šest avtorskih predstav. Prva je bil plesni prvenec Hitchickove metamorfoze s skladateljem Mitjem Reichenbergom (2001), sledil pa mu je solo Kaprica (2005); ta je bil že bolj osredotočen na glas, ki pa ga je avtorica še intenzivneje razvila v kasnejših predstavah. Leta 2006 je na festivalu Mesto žensk predstavila remake predstave Kaprica z naslovom (S)pozaba kaprice, sledila je Kot kaplja dežja v usta molka (2008), za katero je na festivalu Gibanica 2009 prejela posebno pohvalo žirije kot obetavna koreografinja. Leta 2010 je v sodelovanju z Joséphine Evrard nastala predstava Splet okoliščin, leta 2012 pa solistična predstava Okus tišine vedno odmeva, za katero je na festivalu Gibanica 2015 prejela nagrado žirije in nagrado občinstva za najboljšo predstavo. Leta 2015 je pripravila avdio-video instalacijo Obrazi glasov/šum, ki ji je sledila solo predstava Telo glasu. Izdala je tudi dva avtorska albuma. 
Telo je tako fizično v svoji fenomenalnosti, ki je v veliki meri zvočna, hkrati pa proizvaja pogojno semiotične pomene, ki z obrobja gledališke semiosfere prodirajo $\mathrm{v}$ njeno središče. $\mathrm{V}$ svojih zvočnih performansih, na primer $\mathrm{v}$ predstavi $\operatorname{Mes}(t)_{0}$ glasu, ${ }^{5}$ raziskuje odnos med telesom, glasom in prostorom ter se posveča raziskovanju mnogoterih izvorov glasu, njegove mesenosti, materialnosti in duhovnosti, njegovega pomena in mesta $\mathrm{v}$ vsakdanjem življenju. Zanimajo jo točke oziroma prehodi $\mathrm{v}$ prostoru in času, ko »volja kultiviranega mesa popusti in dopusti« ter se »zgodi glas kot oživljanje in prisluškovanje mnogoteremu zvočnemu prostoru znotraj in zunaj posameznega in skupnega telesa? Telesa, ki posluša in rezonira s slišanim. Glas je včasih otipljiv in neposredno vstopa $\mathrm{v}$ telo, bližina tega mesta pa nam je zaradi pozabe in odtujitve naše najbolj mesene notranjosti čudno tuja. $\ll^{6}$

Zvoka v prostoru ne raziskuje skozi sinestezijo, ampak skozi omogočanje in beleženje glasu v prostoru, ki je $\mathrm{v}$ tesni interakciji $\mathrm{z}$ raziskavo telesnega giba $\mathrm{v}$ mediju sodobnega plesa. Glas in gib sta organsko povezana, prvega $\mathrm{v}$ pogovoru za Radio Slovenija definira (ne brez podobnosti z Wilsonom) takole: »Glas, ki ga ne le slišimo, temveč tudi vidimo. Glas, ki ga zaradi njegove vibracije začutimo v telesu. Glas, ki je melodija, zvočnost, tekstura, frekvenca. ${ }^{7}$

Kot avtoričino zgodbo povzame Alja Lobnik, je »njeno zanimanje za raziskovanje glasu prišlo razmeroma pozno, ko se ji je leta 2005 na Dunaju v okviru Dance Weba na festivalu ImPulsTanz kot že formirani plesalki nenadoma odprl nov teritorij raziskovanja, materialnost glasu. Pognala se je $\mathrm{v}$ raziskovanje nekega drugega telesa, ki lahko s fizičnim vstopa $\mathrm{v}$ paralelna gibanja ali antagonistično kljubuje in razpleta konvencionalno vez giba in zvoka« (Lobnik, nepaginirano). Usmerila se je $\mathrm{v}$ raziskovanje uprostorjenja glasu, kako glas kljub liminalnosti, ki je ena njegovih bistvenih lastnosti, zajeti v odrsko postavitev.

Različne odnose med glasom in prostorom, ki jih raziskuje, ob predstavi (S)pozaba kaprice (2006) Irena Tomažin Zagoričnik opiše takole:

Prazen prostor je treba šele vzpostaviti, tako kot tišino. Izriše se z (neslišnim) glasom. Ta deluje kot horizont, kamor se vpišejo ostali. Je glas, za katerega se zdi, da ne obstaja, ker je neslišen in samoumeven. Glas prostora. Vanj je umeščen glas, ki se je enkrat že uglasil in se izpel. Deluje in je prisoten samo kot spomin na nekaj preteklega, nekaj že dovršenega - kot posnetek, kot nekaj

$5 \quad$ Mes(t)o glasu: avtorica koncepta: Irena Tomažin Zagoričnik; soustvarjalke in izvajalke: Adriana Josipović, Nika Rozman, Irena Tomažin Zagoričnik, Nataša Živković; dramaturgija: Barbara Korun; zvočni prostor: Tomaž Grom ... Produkcija: EMANAT. Koprodukcija: Zavod Sploh. Premiera: 7. 12. 2017, Stara mestna elektrarna - Elektro Ljubljana.

6 https://emanat.si/si/produkcija/irena-tomazin-zagori\%C4\%8Dnik--mesto-glasu/ [29. 9. 2019]

7 Oder, 20. februar 2018; https://4d.rtvslo.si/arhiv/oder/174521544 [29. 9. 2019] 
napol izbrisanega, iznakaženega, premeščenega. Je glas, za katerega se zdi, da ne obstaja, ker je stvar preteklosti. Glas spomina. Z njim si prostor deli in ga sooblikuje glas, ki na licu mesta vznika, se zapleta med luknje spomina in izginja v njem, ko pušča sledi, ko pušča zaznamovano tišino. Je glas, za katerega se zdi, da ne obstaja, ker z vznikanjem že izginja. Glas telesa. ${ }^{8}$

Zdi se, da lahko naravo raziskav Irene Tomažin Zagoričnik v Lotmanovo terminologijo prevedemo nekako takole: $\mathrm{v}$ teh predstavah-raziskavah oziroma glasovnih performansih gledališka in uprizoritvena semiosfera v klasičnem pomenu s pomočjo »meje« vzpostavlja stik z »nesemiotičnim « in »tujesemiotičnim « prostorom (Lotman, 2006, 14-15), ki ga predstavljajo nesemantično zasnovane glasovne modulacije telesa v prostoru. Pri tem se pri gledalcu (pa tudi ustvarjalki) sprožajo posebni mehanizmi prevoda, ki omogočajo posredovanje tujih kontaktov, "zaumnih" glasovnih mas, ki pripadajo mejni strukturi.

Če Lotman poudarja, da semiotični procesi pospešeno potekajo na periferiji kulturnega prostranstva (prav tam, 15) in da so v primerjavi s tistimi, ki se razvijajo $\mathrm{v}$ »centrih « ali jedrih (nuclei), bolj dinamični (prav tam, 16), to še posebej velja za performativno-raziskovalne projekte sodobnih odrskih umetnosti, ki preizprašujejo in povezujejo medije. Razmerje med jedri in periferijo, ki je v sodobni umetnosti nekaj, kar ni stalno, ampak se nenehno spreminja, omogoča prehajanje iz semiotičnih v nesemiotične prostore, posebne kreativne in receptivne procese, ki težijo h kreaciji drugih in drugačnih semiotičnih prostorov. Semiotični procesi težijo k čedalje večji notranji raznolikosti, ne da bi semiosfera pri tem izgubila svojo enotnost (prav tam, 20).

\section{Dramaturgija svetlobe, giba in zvoka}

Posebna medkulturna in medmedijska dinamika semiotičnih procesov, ki potekajo na periferiji kulturnega prostranstva in se katapultirajo v njegova središča, na primer London in Pariz, je značilna za izraelsko-britanskega koreografa, režiserja in glasbenika Hofesha Shechterja ${ }^{9}$ in njegovo skupino, ki bo tretji predmet naše raziskave politike prostora. Predstava, ki jo bomo izpostavili, je Show, ki je med drugim prejela

8 http://mrezni-muzej.mg-lj.si/si/mreznimuzej/1/31/?artworkid=931 [29. 9. 2019]

9 Rojen v Jeruzalemu je kariero začel z Batsheva Dance Company v času služenja vojaškega roka. Potem se je preselil v Pariz, kjer je študiral glasbo in igral bobne v rock bandu The Human Beings. Leta 2002 se je s skupino preselil v London, kjer je sodeloval z Jasmin Vardimon Company, se preizkusil v solu in duetu Fragments ter postal pridruženi koreograf Place Theatra. Istega leta je njegov sekstet Cult prejel nagrado občinstva. V Placeu je nadaljeval kariero s predstavo za sedem plesalcev Uprising (2006). Od takrat naprej se je vzpenjal po lestvici najbolj kontroverznih in iskanih koreografov ter začel sodelovati z najprestižnejšimi baletnimi in plesnimi hišami. 
nagrado za najboljšo izvedbo v Les Abesses Théâtre de la Ville v Parizu leta 2018. ${ }^{10}$ Hibridni žanr, ki ga je kritika označila s sintagmo elektrobaročni veliki ples, povezuje nepovezljivo: antologijo plesnih, gibalnih, uprizoritvenih, glasbenih in vizualnih tehnik, od najbolj kodificiranega sarabandskega plesa do plemenskih ritualov, z glasbo od tehna do renesančnih in baročnih plesov ter mediteranske folklore. Vse to se povezuje $\mathrm{v}$ uprizoritveni svet macabre mehanizmov sanjske, a krute resničnosti. Predstava, ki je nastala za sloviti Nederlands Dans Theater, je kasneje dobila nov vzgib v skupini izjemno mladih in tehnično raznolikih izvajalk in izvajalcev, od sodobnega baleta do novega cirkusa in klovnad.

$\mathrm{Na}$ videz je sestavljena iz treh klasičnih enot: The Entrance (Vhod), Clowns (Klovni) in Exit (Izhod). Naslovi so heterogeni, prvi in zadnji kažeta na strukturiranje po sistemu uvoda in finala, a imata pomena, ki sta bolj kot za dele plesno-glasbene partiture primerna za označevanje stavbe gledališča ali dogajališča nasploh. Tretji del, ki je dodelava koreografije za NDT, pa ima naslov, ki asociira na Federica Fellinija in njegov film Klovni, hkrati pa kaže na hibridno strukturo predstave, ki črpa iz cirkusa kot uprizoritvene zvrsti s samega obrobja gledališke semiosfere.

Temi, ki ju odpira, sta provokativni: norost in smrt; obe obdeluje s pomočjo ritualov ponavljanja, smrti, ubojev in ponovnih rojstev. Plesalci-izvajalci v ponavljajočem se in hitrem ritmu umrejo, da bi ponovno vstali in ponavljali svoj šamanistični novodobni ritual, ki je v veliki meri ritual nasilja, koreografove mladosti in odraščanja, Jeruzalema, in današnjega časa, velikih multikulturnih metropol, Londona, množičnih in ponavljajočih se ubojev z bodali; remakov scen rezanja grl, ki jih spremlja in poganja pulzirajoča glasba različnih žanrov.

Začetni prizor z osmimi uporniško navdahnjenimi izvajalci, ki jih osvetljuje nekaj svetilk ter se iz ozadja odra ob ritmih, ki prehajajo v crescendo, počasi in nekoliko zlovešče približujejo publiki, gledalce vpelje v svet, v katerem vladajo norci in v katerem je vse mogoče. Ta svet uokvirja prostor, ki ga obrobljajo viseče žarnice, spominjajoče na napol zapuščeni cirkus, ki ga naseljujejo klovnovske figure in akrobati. Njihov ponavljajoči se ritual je ubijanje drug drugega, ponovno oživljanje in spet ubijanje vse do popolne izčrpanosti. Telesa so neprestano v gibanju, ki je (po koreografovi razlagi) kombinacija vseh stvari, ki jih obvlada ali jim je bil izpostavljen, mešanica urbanih groovov, ljudskih plesov in klasičnih referenc. Hkrati Show preveva konflikt med mediji in nasiljem socialnih omrežij, kot sta Twitter in Facebook. Kot da bi bilo vse, tudi nasilje, v mediatizirani družbi spektakla do skrajnosti podvrženo zabavi: entertainmentu. Od tod tudi naslov: Show.

10 SHOW je doživel premiero v Teatro Ariosto Reggio Emilia 17. marca 2018; koreografija in glasba Hofesh Shechter, izvaja skupina Shechter II. Predstavo smo si ogledali 23. marca 2019 v Théâtre des Abbesses, Théâtre de la Ville v Parizu. 
Pomemben element prostorske dramaturgije Shechterjevih predstav je dramaturgija svetlobe, $v$ kateri svetlobne spremembe in dinamika generirajo scenske in scenografske materiale, proizvajajo temo ter izvajalce postavljajo $\mathrm{v}$ interakcijo $\mathrm{z}$ živim in pomenov polnim okoljem. Luč ustvarja pogoje, v katerih se srečujejo telesa, prostor, gibi in geste. Še več, prav svetloba in dinamika njenih sprememb ustvarjata posebno dinamiko percepcijskih stanj.

Zdi se, da je prav v dinamičnem plesnem in fizičnem gledališču svetloba postala eden poglavitnih generatorjev procesov semioze, $\mathrm{v}$ kateri se ustvarja dinamika med obrobjem in središčem, semiotičnimi in nesemiotičnimi sistemi ter pomeni, značilna za sodobne uprizoritvene prakse in njihovo prostorsko dinamiko. Nigel Stewart (2016) tako govori o »dance photology« ali plesni fotologiji, ki v sodobnem plesu zajema medsebojno delovanje med premiki in svetlobo.

Lahko bi rekli, da Shechter ustvarja to, kar Lotman poimenuje "periferni žanri«, ki so po njegovem mnenju »bolj revolucionarni od tistih v centru kulture, veljajo za bolj prestižne in za sodobnike pomenijo umetnost par excellence« (Lotman, 2006, 189). Toda za spektakelske funkcije v prvi polovici 21. stoletja se ne zdi, da bi še delovale po klasičnem sistemu postopnega prodiranja marginalnih oblik kulture iz obrobja semiosfere v njeno središče. Danes se zdi, da so v družbi spektakla marginalne kulture zelo hitro podvržene poblagovljenju in eksploataciji, tako da se proces »agresije marginalnih kultur«, kot ga označi Lotman, dogaja bliskovito, predvsem pa skozi prisvajanje mainstreama, ki to, kar Lotman poimenuje "puntarska periferija", hitro pripoji poblagovljenemu svetu »mainstream bizzare« (če uporabimo pojem mehiškega teoretika Guillerma Gómez-Peñe). Sodobni umetniki so zato kot nomadi, ki so se naselili ob mejah središčne kulture, se povezali z njenimi nosilci in prevzeli njihovo vero, ne da bi zares verovali.

\section{Postdramska dramaturgija prehajanja meja}

Zadnje polje raziskave bodo predstavljali trije odrski odsevi klasike Lewisa Carrolla Alice in Wonderland, tj. predstave Vita Tauferja, Emmanuela Demarcy-Mote in Maria Punza: prvi dve kot izjemni kreaciji za mlade gledalce, ki raziskave odrskega prostora in časa združujeta s senzibiliteto za otroško publiko, Tauferjeva (Slovensko mladinsko gledališče, 1987) iz poznega socializma in zgleden primer slovenske variante gledališča podob, Emmanuele Demarcy-Motejeva (Théâtre de la ville, Pariz, 2015) kot sodobna pravljica o sodobni resničnosti, v katero skozi domišljijo in hkrati kritični odnos do poblagovljene družbe spektakla vstopajo mlajši in najmlajši, in tretja kot antropološka raziskava zaporskega gledališča Volterre iz leta 2009. 
Tauferjevo predstavo zaznamujejo močni poudarki v polju postdramskega in gledališča podob. Če je njegov izstop iz aristotelovske dramaturgije in »teološkega odra (Derrida, 1967) prinesla predstava Jaz nisem jaz I, ki je s svojo intermedijsko zasnovo (slikar: Sergej Kapus; scenograf: Iztok Osojnik; glasba v živo: Srp; koreografija: Ksenija Hribar; maske: Eka Vogelnik; slide show: Bojan Brecelj ...) uveljavila gledališče, ki pomeni način postdramskega prepletanja "podobe-giba-glasbe-tekstatehnologije«, je Alica v čudežni deželi v dialogu s Carrollom izpostavila gledališče, v katerem "so poudarjene slikarske in kiparske kvalitete predstave, zaradi katerih se to gledališče transformira $\mathrm{v}$ prostorsko dominirano umetnost, ki jo aktivira občutek vtisov (impresij), kar je nasprotje časovno dominirane umetnosti, ki ji vlada linearna pripoved« (Marranca, 1977, xii). Zanj je bil značilen tableau kot osrednja enota kompozicije predstave.

Taufer je v predstavi tableauju v dialogu z Artaudom dekonstruiral Carrollov nonsens, hkrati prebiral oba, ob tem pa tudi zgodovino gledališča. Carrolla in dramsko gledališče je prevajal tako, da je ustvaril - če citiramo Deleuza, ko govori o Artaudu - »neko osrednje in ustvarjalno porušenje, ki povzroči, da se znajdemo v nekem drugem svetu in nekem drugem jeziku« (Deleuze, 1998, 87). Ta drugi svet in drugi jezik pripadata razhierarhiziranemu gledališču podob, v katerem »vizualne in govorne podobe« (Marranca, 1977) na eni strani »dekonstruirajo, prelagajo in postavljajo pod vprašaj spraševanje o samem pojmu, logiki in teleološki strukturi političnega " (Lehmann, 2002, 8), na drugi strani pa dekonstruirajo samo podstat dramskega gledališča in njegove reprezentacije. Aličino popotovanje po prostorskih in časovnih ploskvah predstave tako $» \mathrm{z}$ montažo virtualnih prostorov, ki so potisnjeni drug $\mathrm{v}$ drugega in drug poleg drugega in - to je ključna točka - ostanejo med seboj neodvisni, tako da ne omogočajo sinteze, nastane poetična sfera konotacij« (Lehmann, 2003, 97).

Emmanuel Demarcy-Mota svojo Alico in druga čudesa (Alice et autres merveilles) postavlja hkrati v sedanji svet otrok taktilnih ekranov in mitski svet Lewisa Carrolla ter pri tem ustvari svojevrsten hommage Robertu Wilsonu in njegovemu gledališču podob v variantah za odrasle in otroke (na primer njegove predstave Peter Pan). Uporabi njegov sistem pripovedovanja zgodb s pomočjo arhitekture teles, prostora, zvoka, barv in kostumov ter seveda tudi Carrollovega nonsensa, ki proizvaja svobodo nelogocentrične govorice in posebno geometrijo predstave. Ta je hkrati kubistična in evklidovska. Vprašanje, ki si ga zastavlja skupaj s Carrollom in Alico, je naslednje: in tudi če svet nima nikakršnega smisla, kdo nam brani, da si ga izmislimo sami? Predstavo oblikuje skupaj s Carrollovimi liki, na primer Klobučarjem in Belim zajcem, ki pa jim dodaja nove iz mitologij 20. in 21. stoletja: Ostržka (Pinocchia) in Barbiko, ki nenavadno spominja na Rito Hayworth. 
Pri tem se zdi režiserju bistveno, da lahko vsak igralec izoblikuje lasten imaginarij, svobodno izumlja svojo osebo in da duška svoji fantaziji. Prvotno Carrollovo zamisel, da bi se Alica najprej vrnila v podzemlje, se potem spet vrnila na površje ter ugledala stvari v drugačni luči in drugačnem prostoru, Demarcy-Mota zamenja s perspektivo plavalca, ki hkrati lahko zre v dva svetova, pod vodno gladino in nad njo. In res je odrski prostor Alice in drugih čudes prekrit z vodo, ki je hkrati ogledalo ter prostor za svobodo nenavadnih gibov in svobodne igre nadrealističnih prikazni, ki se v drugem delu približajo univerzumu Tima Burtona ter uporniškosti Pink Floydov in The Cure. Vse to priča o tem, da se kultura danes verjetno še bolj kot kdaj koli dogaja na mejah, ki hkrati ločujejo in združujejo - na mejah jezikov, kultur, slogov, medijev in ideologij. Tako rekoč vsi marginalni jeziki uprizoritvenih praks se $\mathrm{z}$ vratolomno hitrostjo prevajajo v jezike »naše» semiotike, in sicer skozi membrane, ki tuje tekste (glasbe ...) filtrirajo in transformirajo tako, da se lahko zelo hitro vpišejo v notranjo semiotiko semiosfere, a ji hkrati ostajajo tuji (Lotman, 2006, 193).

Posebno obliko prevajanja $\mathrm{v}$ jezik gledališke semiotike skozi membrane, ki filtrirajo in transformirajo tuje tekste (glasbe ...), je ustvaril Armando Punzo z nenavadno predstavo iz leta 2009, ki jo je esejistično naslovil Alica v čudežni deželi: gledališki esej o koncu civilizacije (Alice nel paese delle meraviglie - Saggio sulla fine di una civiltà) ter je del njegovega dolgoletnega delovanja in ustvarjanja $\mathrm{v}$ zaporih $\mathrm{v}$ Volterri. V primerjavi s predstavama Tauferja in Demarcy-Mote je njegova verzija Alice le ohlapno povezana $\mathrm{z}$ mojstrovino Lewisa Carrolla. Besedilno veže govorne ploskve, monologe in dialoge drugih avtorjev, kot so Shakespeare (predvsem Hamlet), Genet, Pinter, Čehov in Heiner Müller. Izvajajo jo zaporniki, ki prestajajo različne kazni (od petih let do dosmrtne ječe). Ti v pogledališčenih prostorih kaznilnice v »Tragediji moči« (tako je podnaslovil predstavo) s pomočjo recitiranja, branja ali dobesedno žretja in bljuvanja Shakespearja, Carrolla in Geneta, potem pa še povezovanja njihovih besed $\mathrm{z}$ besedami avtorjev, kot so Carmelo Bene, Čehov in drugi, izvajajo poseben gledališki in očiščevalni ritual. Alica (igra jo edina ženska izvajalka) se znajde v labirintu, v katerem Carroll izgine; obkrožajo nas ogromni listi papirja, popisani s črno-belo pisavo Hamleta, Ofelije, Polonija, Gertrude in drugih duhov.

Prostor tako kot vizualno ustvarja v vsej njegovi dinamiki tudi glasovno-zvočno in kinetično, okoli nas je gozd glasov in teles številnih moških igralcev, oblečenih v ženske, ki predstavljajo Norega klobučarja, Ofelijo, Hamleta in temnopolto vlačugo v roza škornjih. Zapor v Volterri je radikalno spremenil svojo namembnost, spremenil se je $\mathrm{v}$ prostore Artaudovega gledališča kuge in dvojnikov, ki nas nagovarjajo in nam govorijo, kako mora gledališče prikazati vse na način ljubezni, zločina, vojne in norosti. Punzo svoj odrski esej gradi na eklektičnosti dinamike prepleta teles in zvokov 
v na videz neskončnih prostorih kaznilnice. Na samem obrobju kulturne semiosfere, ki ga predstavlja zapor, vzpostavlja nove uprizoritvene tehnike, nove semiotične in fenomenalne prostore Alice v deželi ječ, ki od daleč spominja na tisto Vita Tauferja ter njegovih komentarjev ječ in svobodnih teritorijev poznega socializma. Hkrati pa podobno kot Demarcy-Mota ustvarja močne odslikave realnosti tukaj in zdaj v pravljičnih in mitoloških motivih in ikonografijah.

\section{Uprizoritveni prostor kot prevajalec}

$\mathrm{O}$ čem pričajo tri verzije gledaliških dialogov sodobnih režiserjev z Lewisom Carrollom in njegovo slovito knjigo s konca 19. stoletja? Brez dvoma o tem, da je elementarni akt gledališča (tako kot trdi Lotman za mišljenje) prevod, ki izhaja iz dialoga. Tega povzroči razlika semiotičnih struktur (jezikov literature in gledališča) udeležencev dialoga, Carrolla in treh umetniških ekip. Dialog črpa iz semiotičnih razlik, hkrati pa tudi iz podobnosti, saj popolna razlika ne bi mogla rezultirati $\mathrm{v}$ ustvarjalnem dialogu.

Za vse tri predstave je značilna specifična dramaturgija, ki v enaki meri kot iz besedilnih izhaja iz prostorskih načel, ki velikokrat oblikujejo zgodbo ali siže. Vse tri predstave (podobno kot Wilsonova) izpostavljajo vmesni položaj gledališča med gibljivim in negibljivim svetom upodabljajočih umetnosti (Lotman). Vzpostavljajo prostor igre (če uporabimo termin Mete Hočevar), ki je izrazito kronotopičen in dinamičen v smislu prehajanj meja znotraj Lotmanove semiosfere. Izhajajoč iz Carrolla in njegovega nonsensa so predstave v dramaturgiji velikokrat nepredvidljive in fluidne, ne proizvajajo enega snopa zgodb in pomenov, kaj šele ideologij. Težko bi rekli, da izhajajo iz Wilsonovega prepričanja, da je bolj kot »realizem« na odru produktiven formalizem. Toda kljub temu ne gradijo na realistični naraciji in tudi ne izgrajujejo mimezisa realnosti, ampak nove, specifično gledališke in avtorske prostore za resnično.

Naj povzamemo. Kot je pokazala analiza izbranih uprizoritvenih korpusov, je tudi v sodobnem gledališču predstava semiotični prostor prestopanja oziroma prehodnih oblik, ki nastajajo med različnimi mediji. Hkrati beleži tudi proces prestopanja meja med odrom in avditorijem, igralci in gledalci, posebne dinamike avtopoetične povratne zanke. $\mathrm{V}$ sodobnih uprizoritvenih praksah, ki pogosto povezujejo različne medije, žanre in kulture, prostor igre in gledanja (kot smo lahko videli v obravnavanih primerih) velikokrat postane stvar prevajanja v Bourriaudovem smislu: umetniki prevajajo in prekodirajo informacije iz enega formata $v$ drugega. Gledališka umetnost $\mathrm{v}$ najširšem smislu besede tako postane raziskovanje vezi, ki se pletejo med besedo in sliko, časom in prostorom. Za gledališki prostor pa postane značilno prehajanje 
iz ene kulturne krajine $\mathrm{v}$ drugo, ki ustvarja nove poti med množico izraznih in komunikacijskih oblik.

Tako nastane dinamika semiotičnih jezikov $\mathrm{v}$ prostoru, ki ga Lehmann $\mathrm{v}$ Postdramskem gledališču poimenuje "postdramski prostor» in za katerega najde podobne značilnosti, kot jih ob Lotmanovi teoriji in sodobnih primerih nizamo $\mathrm{v}$ naši razpravi: iztrganost teles, gest, drže in glasov ter gibanja iz njegovega prostorskočasovnega kontinuuma ter nova povezanost, izolacija in montaža v tableau, za katerega ni več značilna hierarhija dramskega prostora (Lehmann, 2003, 199). Prostor in čas gledališke predstave tako nista več enostavna vsota posameznih znakovnih sistemov, ampak v interaktivnosti vzpostavljata gledališki dogodek kot tak. Za tovrstne dogodke je značilna tudi specifična recepcija. Ta v smislu Rancièrjevega emancipiranega gledalca uvede posebno dramaturgijo percepcije, ki je hkrati govorna in prostorska, zvočna in govorna.

Igralci-izvajalci suvereno gradijo oder, gledalci pa so aktivni interpreti, ki kreirajo lasten prevod, za katerega je značilen kreativen preplet med besedo in sliko, časom in prostorom. $\mathrm{V}$ smislu Bonnie Marranca ter njenega razumevanja gledališča podob in Lotmanovega razumevanja umetniških del kot sistemov delovanja jezikov, ki zapolnjujejo "semiotično prostranstvo« predstave, v tovrstnih gledaliških korpusih nastane posebna dinamika prostora in časa, za katero je značilno prehajanje oziroma prebijanje meja znotraj polja kreacije in recepcije. Sodobno gledališče v procesu semioze prostor, svetlobo, zvok in gibanje tke oziroma prepleta v odprto, nenavadno tkanino, ki na eni strani proizvaja pomene, na drugi strani pa estetski užitek, oba pa spremlja postbrechtovska drža zavedanja o tem, da lahko umetnost kljub vsemu vzpostavlja vsaj začasno skupnost med izvajalci in gledalci v skupnem prostoru odra in avditorija, ki omogoča začasno povratno zanko.

Lotmanov koncept semiosfere kot ekosistema, ki zajema tako prostor kot čas predstave, okoljski in ekonomski vidik ter politično okolje, ki obdaja gledališki dogodek, se zdi še kako uporaben tudi za teorijo gledališča po prostorskem obratu ter v postkolonialnem in interkulturnem okolju. Lahko ga navežemo in povežemo z novejšimi teorijami, na primer postdramskega prostora, centrifugalne in centripetalne dinamike pri Lehmannu ali z estetiko performativnega ter performativnega prostora Erike Fischer Lichte, ki se v primerjavi s stabilnim arhitekturnim prostorom »spreminja Z vsakim gibom igralca, živali, predmeta, luči in zvoka« (Fischer-Lichte, 2008, 180). Tako v sodobnih uprizoritvenih praksah nastajajo posebni prostorski odnosi in politike prostora. Definirana kot nekaj, kar je v nenehnem procesu transformacije, je semiosfera ves čas v gibanju ter se ves čas zaveda, da je del kompleksne dramaturgije odnosa med odrom in avditorijem, primarno odvisnega od performativnih dejanj, s pomočjo 
katerih proizvaja gibljive in nefiksirane pomene. Lotman zato gledališko predstavo $\mathrm{v}$ knjigi Znotraj mislečih svetov primerja $\mathrm{z}$ razstavo, $\mathrm{v}$ kateri $\mathrm{v}$ istem časovnem intervalu soobstajajo številni znakovni sistemi, saj je predstava večnivojska in večjezična ter kot taka generira mehanizem, ki vzpostavlja podobo semiosfere dinamičnih soodnosov med posameznimi elementi.

\section{Bibliografiija}

Aronson, A., Time and Space on the Stage, Performance Research 18, 3, 2013 (On Scenography), str. 84-94.

Bourriaud, N., Altermodern explained: manifesto, 2009a, https://www.tate.org. $\mathrm{uk} /$ whats-on/tate-britain/exhibition/altermodern/altermodern-explainaltermodern/altermodern-explained [30. 10. 2019].

Bourriaud, N., The Radicant, New York 2009b.

Deleuze, G., Logika smisla, Ljubljana 1998.

Derrida, J., Lécriture et la différence, Pariz 1967.

Fischer-Lichte, E., The Transformative Power of Performance: A New Aesthetics, New York 2008.

Fischer-Lichte, E., Wihstutz, B., Performance and the Politics of Space, London 2012.

Gómez-Peña, G., The New Global Culture, Somewhere between Corporate Multiculturalism and the Mainstream Bizarre (a border perspective), TDR/The Drama Review 45, 1, 2001, str. 7-30.

Lefebvre, H., La production de l'espace, Pariz 1974.

Lobnik, A., Glasovanja, Kriterij.si, http://www.kriterij.si/node/36\#_ftn2 [29. 9. 2019].

Lehmann, H. T., Politično v postdramskem, Maska XVII, 74/75, 2002, str. 6-10.

Lehmann, H. T., Postdramsko gledališče, Ljubljana 2003.

Lotman, J. M., Znotraj mislečih svetov: človek - tekst - semiosfera - zgodovina, Ljubljana 2006.

Marranca, B. (ur.), The Theatre of Images, Baltimore, London 1977 (1996).

McAuley, G., Space in Performance: Making Meaning in the Theatre, Ann Arbor, MI 2000.

Rancière, J., Le spectateur émancipé, Pariz 2008.

Schechner, R., Friedman, D., Wilson, R., Newman, F.: A Dialogue on Politics and Therapy, Stillness and Vaudeville, TDR 47, 3, Autumn 2003, str. 113-128.

Stewart, N., Flickering Photology: Turning Bodies and Textures of Light, v: Choreography and Corporeality (ur. DeFrantz, T., Rothfield, P.), London 2016. 
Taylor, H., Deep dramaturgy: Excavating the Dramaturgy of the Site-Specific Performance, Canadian Theatre Review 19, Summer 2004, str. 16-19.

Toporišič, T., (Re)staging the rhetorics of space, Neohelicon 41, 1, June 2014, str. 77-86. 


\section{Tomaž Toporišič}

\section{Prostorski stroji gledališča kot dinamika prestopanja meja semiotičnih sistemov}

Ključne besede: Robert Wilson, Emmanuel Demarcy-Mota, Vito Taufer, prostorski obrat, prostorska dramaturgija, dramaturgija zvoka, semiosfera

Razprava bo na podlagi študije šestih primerov iz sodobne gledališke in uprizoritvene prakse preverjala, kako lahko Lotmanov koncept semiosfere kot ekosistema, ki zajema tako prostor kot čas predstave, okoljski in ekonomski vidik ter politično okolje, ki obdaja gledališki dogodek, uporabimo za teorijo gledališča po prostorskem obratu ter $\mathrm{v}$ postkolonialnem in interkulturnem okolju. Njegov pojem semiosfere kot prostorsko-časovnega fenomena, kombinacije različnih (ne) verbalnih jezikov, ki so $\mathrm{v}$ neprestanem dialogu drug z drugim, bomo uporabili za analizo prostorskih odnosov in politik prostora v sodobnih uprizoritvenih praksah, da bi odkrili, na kakšen način uprizarjanje ustvarja semiotične jezike, ki niso enostavna vsota posameznih znakovnih sistemov, ampak v dinamični interaktivnosti vzpostavljajo gledališki dogodek. Predmet analize bodo gledališke predstave kot semiotični prostori prehodnih oblik, ki nastajajo med različnimi mediji, prestopanja meja med odrom in avditorijem ter spremembe dinamike odnosov med igralci in gledalci v procesu kreacije in recepcije. Lotmanov "vmesni položaj gledališča med gibljivim in nediskretnim svetom realnosti ter negibljivim in diskretnim svetom upodabljajočih umetnosti« (Znotraj mislečih svetov) bomo navezali na Rancièrjev pojem emancipiranega gledalca in Bourriaudov pojem prevajanja, umetnosti kot raziskovanja vezi, ki se pletejo med besedo in sliko, časom in prostorom. Raziskali bomo dinamiko semiotičnih jezikov v prostoru, ki niso enostavna vsota posameznih znakovnih sistemov, ampak v interaktivnosti vzpostavljajo gledališki dogodek. 


\section{Tomaž Toporišič}

\section{Spatial Machines of the Theatre as the Dynamics of Crossing the Boundaries of Semiotic Systems}

Keywords: Robert Wilson, Emmanuel Demarcy-Mota, Vito Taufer, spatial turn, spatial dramaturgy, dramaturgy of sound, semiosphere

On the basis of a study of six examples from contemporary theatre and performing arts, the essay will examine how Lotman's concept of the semiosphere as an ecosystem covering both the space and time of performance can be applied to the environmental, economic and political aspects of the theatrical within the post-colonial and intercultural space. His notion of the semiosphere as a spatio-temporal phenomenon, a combination of different (non)verbal languages that are in constant dialogue with one another, will be used for the analysis of spatial relations and space policies within contemporary performing arts in order to discover how the act of mise en scène creates semiotic languages, which are not a simple sum of individual systems, but are characterised as a dynamic interactivity, establishing the theatrical event. The subject of the analysis will be theatrical performances as semiotic spaces of transitional forms that arise between different media, the crossing of the boundaries between the stage and the auditorium, changes in the dynamics of relations between actors and spectators within the process of creation and reception. We will link Lotman's "theatre's position as an intermediary between the moving and nondiscrete real world and the immobile and discrete world of the representational arts" (Lotman, Universe of the Mind) to Jacques Rancière's notion of an emancipated spectator and Nicolas Bourriaud's notion of translation, art as an exploration of the bonds that engulf the word and picture, time, and space. Our aim will be to research the dynamics of semiotic languages within space, the interactivity they establish within performative practice. 